\title{
Preserving the heritage of limnology in Italy
}

\author{
Roberto Bertoni, ${ }^{1 *}$ Filippo Bertoni ${ }^{2}$ \\ ${ }^{1}$ National Research Council, Water Research Institute, Largo Tonolli 50, 28922 Verbania Pallanza, Italy; ${ }^{2}$ Humanities of Nature, Museum \\ für Naturkunde, Berlin, Germany
}

\begin{abstract}
This article is simultaneously a call for, a study of, and a contribution to the preservation of scientific heritage. Focusing on the heritage of a disciplinary niche like that of limnology, we take the specific heritage of the Istituto Italiano di Idrobiologia 'Dr. Marco De Marchi' (Istituto) as a case study to illustrate the present challenges and possibilities for the conservation and study of limnological scientific heritage. In particular, we highlight two different forms that this heritage takes at the Istituto: its ongoing scientific publication - the current Journal of Limnology, and its collection of scientific instruments - the Crypta Baldi. Showing both the limitations and potential of these collections, we offer insights into the history of limnology through the lens of the Istituto. Furthermore, we bring these insights to bear on broader reflections about the importance of preserving the scientific heritage that shaped and continues to shape our world, and holds the promise of helping us not to lose sight of the past as well as the future of a scientific field like limnology.
\end{abstract}

\section{INTRODUCTION}

The natural sciences have profoundly shaped the history of our world. Yet, as they tend to be valued for their factual and objective contributions to a universal body of knowledge, their historical vicissitudes are often overlooked (or, at best, anecdotal). Furthering this common misconception, science is generally studied, presented, and perceived as separated from its complex history: while it is considered common knowledge that $\mathrm{H}_{2} \mathrm{O}$ is the chemical formula representing the molecular composition of water, the details of how this notation came to be are left to a handful of esoteric specialists (Hasok, 2012). This ahistorical image of science is partly to be blamed for the lag in the preservation of scientific heritage we still witness today. Unlike in the case of more traditional forms of artistic, cultural, and historical heritage that have been the object of early institutional, scientific, legal, and socio-political transnational conservation efforts already since the post-war period,

Corresponding author: roberto.bertoni@irsa.cnr.it

Key words: Istituto Italiano di Idrobiologia; Crypta Baldi; scientific heritage; history of limnology.

Received: 6 April 2021.

Accepted: 3 June 2021.

This work is licensed under a Creative Commons Attribution NonCommercial 4.0 License (CC BY-NC 4.0).

${ }^{\circ}$ Copyright: the Author(s), 2021

Licensee PAGEPress, Italy

J. Limnol., 2021; 80(3):2018

DOI: 10.4081/jlimnol.2021.2018 an international unitary framework to preserve scientific heritage is still forming.

This is evident in the history of UNESCO, the United Nations agency that, since 1976, has been concerned (among other things) with the preservation of the World Heritage of humanity. In 2003, UNESCO broadened its scope, to include intangible heritage to its mandate. This encompasses the practices, representations, expressions, knowledge, and skills - as well as associated instruments, objects, artefacts, and cultural spaces - that communities, groups, and, in some cases, individuals recognize as part of their cultural heritage (UNESCO, 2003). According to Vecco (2010), this is the result of the semantic evolution of the concept of cultural heritage, which has undergone a process of extension over the past decades. While this expanded notion of heritage can well include scientific disciplines and communities, with their own practices, theories, artefacts, and cultures (Van-Präet, 2004), scientific heritage is still largely untouched by the preservation efforts of UNESCO. As others have noted, this is particularly evident in "the limited number of science-related items classified by UNESCO as World Heritage: in a list of almost 1,000, only three qualify as scientific heritage" (Lourenço and Wilson, 2013). Therefore, even if preservation legislation exists and often extends to scientific heritage, the lack of guidance and funding (together with the fear of bureaucratic hurdles) results in few initiatives, mostly left in the hands of national governments, individual institutions, and private interests. This translates in a number of undesirable biases in the preservation of the heritage of science, and a spotty record of the history of scientific practices.

In addressing these problems, this article offers simultaneously a study of, a call for, and a contribution to the preservation of scientific heritage. It does so through the specific history of an often neglected scientific discipline, 
limnology - the science that studies inland waters. As a disciplinary niche within the already too often marginalized area of environmental sciences, limnology offers a good case study in the preservation of scientific heritage. This is because its marginality illustrates well many of the challenges, but also of the potential, involved in the current preservation of this field's heritage. For instance, the way we concentrate our analysis on how limnology unfolded around one specific institution - the Istituto Italiano di Idrobiologia 'Dr. Marco De Marchi'(Istituto)- is symptomatic of the reliance of scientific heritage preservation on already established institutions. In the case of university museums in Italy, this dependence has been instrumental to the success of their preservation (Corradini, 2011). In the case of the Istituto we focus on, though, the already limited reach of this particular Istituto (which, as part of the CNR, falls outside of the jurisdiction of universities) means that the preservation of its heritage mostly depends on the dedication of private individuals, with little institutional support from specialists and virtually no funding. Despite these limitations, though, the Istituto still preserves its scientific heritage in at least two important forms, on which this article expands. The first lies in its publications: the journal published by the Istituto since 1942, the Memorie dell'Istituto italiano di Idrobiologia (Mem.), now Journal of Limnology $(J L)$, not only publishes the outcomes of scientific research, but it also constitutes a living archive of this disciplinary history, as we will show. The second is the collection of scientific instruments hosted in the Crypta Baldi museum, established at the Istituto by one of the authors (RB) already in 2015. Providing a brief overview of how these two resources can help tracing the histories of limnology, we focus on the issue of the preservation of limnological scientific heritage - and its significance for current scientific research. To join in this effort, we also offer two keys to facilitate further research, available as supplementary materials: a searchable list of all the papers published in the Memorie from 1942 until 1998 (suppl. 1); and an informative catalogue of the instruments hosted in the Crypta Baldi museum (suppl. 2). We hope these contributions, together with the analysis offered in what follows, can illustrate the present and pave the way for the future of limnological scientific heritage in Italy and beyond.

\section{Limnology's scientific heritage}

"Scientific heritage is the shared collective legacy of the scientific community, in other words what the scientific community as a whole perceives as representing its identity, worth being passed on to the next generation of scientists and to the general public as well. It includes what we know about life, nature, and the universe, but also how we know it. Its media are both material and immaterial. It encompasses artefacts and specimens, but also laboratories, observatories, landscapes, gardens, collections, savoir faires, research and teaching practices and ethics, documents, and books" (Lourenço and Wilson, 2013)

This definition, which follows and expands UNESCO's framing of intangible cultural heritage to the world of the sciences and their history, highlights the diverse range of what can count as scientific heritage. The breadth and diversity of what is included in this definition, as well as its constant renegotiation, clearly present significant challenges to the conservation of scientific heritage. However, they also make it all the more important for this legacy to be studied, understood, and preserved. To illustrate the importance of scientific heritage, here we consider the broader history of limnology and the significance of its heritage before turning to our case study.

The term limnology was coined by Swiss naturalist François Alphonse Forel in the second half of the $19^{\text {th }}$ century, to denote the scientific study of lakes and distinguish it from oceanography (Vincent and Bertola, 2014). His innovative and comprehensive monograph on Lake Geneva (Forel, 1892) already shows the holistic approach that characterizes this field. Since its beginnings, by concentrating on relatively bounded environments like lakes, limnology developed a cross-disciplinary, holistic, and systemic approach to understand every "lake as a microcosmos" - as another pioneer of the field, the American Stephen Alfred Forbes, famously put it (Forbes, 1887). This interdisciplinarity, combined with the field's relative marginality, resulted in a particularly resourceful and innovative international scientific community, which came together already in 1922 in the Societas Internationalis Limnologiae (SIL) (Egerton, 2014). The particular nature of its object of study - lakes, together with the discipline's holistic approach, granted limnology a prominent role in the consolidation of the now foundational framework of ecology, and its key notion of ecosystem. This is evident, for instance, in the career of Yale limnologist and ecologist Evelyn Hutchinson: his experiments at Lindsey Pond, in Connecticut, established the importance of the biogeochemical and ecological study of trophic dynamics, and lakes' central role in their characterization (Hutchinson, 1957; Egerton, 2016). As the environmental impact of post-war development became a matter of concern over the end of the last century, limnology proved useful in both its theoretical and its applied contributions, as it also became instrumental in addressing pollution and ecosystem management (Egerton, 2018). Today, though, the holistic approach that marked the history of this discipline faces many challenges. The growing specialization in the natural sciences widens the gaps between different approaches; the increased molecular resolution afforded by technological change affects the scaling of scientific research, blindsiding the middle grounds be- 
tween the local and the global; and the exponential rise in the sheer quantity of available data presents entirely novel sociotechnical problems. In addition, changes in the educational trajectories of scientists often pass over the historical depth of scientific endeavours, privileging specialistic training. In the rapidly transforming global landscape of contemporary sciences - with their growing enmeshment in neoliberal capitalism, these challenges bring with them the risk of losing sight of the holistic connections so vital to limnology.

This is where, we argue, the scientific heritage of this discipline can demonstrate its importance. Attending not only to what we know, but also to how we know it (Lourenço and Wilson, 2013), the heritage of limnology can help us address these challenges, while preserving the holistic and cross-disciplinary approach of limnology. As trust in science is eroding, the independence of scientific institutions is encroached upon and besieged, and interdisciplinarity and experimentation are hostages to financial, managerial, and bureaucratic audits in failing governmental and industrial complexes, looking back on our scientific heritage can help us not getting lost. If it is true that this task - of preserving the past of science to protect its future as well - is beyond the scope not only of this article but also of our own limited reach, we still wish to contribute to this effort in a modest way. Hence, we write this call to preserve scientific heritage, which hopefully - also partakes in this effort illustrating part of this history and its value. As Lourenço and Wilson rightly put it: "Perhaps the most important tool to preserve scientific heritage is to study it" (Lourenço \& Wilson, 2013). For this reason, in what remains of this article, we turn to our specific case study, and concentrate on the limnological scientific heritage at the Istituto.

\section{The Istituto Italiano di Idrobiologia}

In the first half of the last century, the increased interest in inland water ecosystems, which were facing increasing anthropogenic pressure, resulted in the establishment of limnological research stations or institutions in different parts of the world. The best known are listed by year of foundation in Tab. 1. Some of them are still active in the field although they have changed their names, while others have ceased their activities or shifted their focus away from limnology (Lampert, 2007).

Among the research station that are still active is the one we concentrate on, the Istituto Italiano di Idrobiologia, established in 1938 and named in memory of its wealthy donor and founder, Marco De Marchi. Since its foundation, the Istituto has been housed in De Marchi's beautiful villa on the coast of Lake Maggiore. In its more than 80 years of existence, the Istituto changed name and affiliation more than once, but it always remained true to its original mandate to contribute to the scientific study of lakes. In 1977, the Istituto became part of the Italian National Research Council (CNR), which led, in 2001, to its reorganization into the Institute of Ecosystem Study (CNR-ISE), and, in 2018, to its current merging with the Water Research Institute (CNR-IRSA). Despite these institutional transitions, the Istituto has maintained a prominent role in the international limnological scientific community thanks to its continued and important research activity. From studies of gene expression, to measures of taxa diversity, abundance, and distribution, from population and trophic dynamics, to microbial ecology, from pollution and acidification, to climate change, the contributions of the Istituto continue the holistic and diverse tradition of limnology (Manca and Bertoni, 2014). However, its scientific contributions do not necessarily translate into scientific heritage: "A bunch of old instruments in the attic of an academic hospital are not scientific heritage per se. They become scientific heritage only after we provide them with a meaning that transcends their mere materiality and therefore justifies their preservation to the next generation. This requires documentation and research into their biographies" (Lourenço and Wilson, 2013). To this end, the institutional history of this research hub can provide a first framework to understand the heritage of the Istituto and its significance and potential for conservation.

Tab. 1. List of the main limnological research station established in the first half of $20^{\text {th }}$ century.

\begin{tabular}{|c|c|c|}
\hline Institution & Country & Established in \\
\hline Max Planck Institute, becoming "Hydrobiological Institute" (https://www.evolbio.mpg.de/15190/history) & Plön, Germany & $1917 *$ \\
\hline Trout Lake Station, University of Wisconsin, Center for Limnology (https://limnology.wisc.edu/) & Madison, USA & 1925 \\
\hline Balaton Limnological Institute (https://www.blki.hu/en) & Tihany, Hungary & 1927 \\
\hline Baikal Limnological Station, Russian Academy of Sciences (http://lin.irk.ru/en) & Irkutsk, Russia & 1928 \\
\hline $\begin{array}{l}\text { Laboratory of Freshwater Biological Association on Lake Windermer } \\
\text { (https://www.fba.org.uk/FBA/Public/WhoWeAre/Heritage.aspx) }\end{array}$ & Wray Castle, UK & $1931^{*}$ \\
\hline $\begin{array}{l}\text { Istituto Italiano di Idrobiologia, since } 2018 \text { part of the Water Research Institute of National Research } \\
\text { Council (http://vb.irsa.cnr.it) }\end{array}$ & Verbania Pallanza, Italy & 1938 \\
\hline
\end{tabular}


Focusing on this particular Istituto, as we already mentioned, allows us to underline the centrality of institutional affiliations in the preservation of scientific heritage: science outside of institutional framings or at its margins is more easily excluded from historical accounts and scientific heritage, and this is true also for limnology. While institutionalization is a crucial first step, though, scientific heritage still faces many challenges even if it emerges in the safe harbour of dedicated institutions. Some of these are clear in the case of the Istituto we focus on. For instance, as a scientific research institute, the preservation of scientific heritage exceeds the official mission of this institution. As a result, specific expertise in the preservation and management of this heritage, as well as its study, fall outside of the scope of the Istituto. In turn, this means that funding is limited, as scientific research needs to be prioritized over the preservation of its heritage. The work of preserving scientific heritage that is possible at the Istituto, then, is significantly limited, as is evident in the paper and photographic documentary archive (Mosello, 2018), which is confined by restricted access and could be offered only in Italian. Linked to the limited funding, is also the limited purview of the Istituto over its own heritage: as part of a national scientific research apparatus like CNR, the Istituto is subject to official decisional hierarchies. This means that most decisions that could affect local scientific heritage are taken somewhere else, and often without consultation with those for whom this heritage is most important, or most familiar. A notable example of this close to the Istituto is the case of villa Monastero, in Varenna, on Lake Como. This was another De Marchi property donated for scientific research; but after having served in a variety of roles for its intended use, it was eventually sold in 2009 , by CNR, to the Province of Lecco. This sale contributed to the preservation of the architectonic and historical heritage of the villa (which is now part museum, part botanical garden, and part conference centre), and resulted in more funding for other local scientific institutions and infrastructures. Yet, it also severed the link with much of its scientific heritage - underlining the downplaying of scientific heritage vis a vis other institutional priorities. Despite these limits, though, there is also hope. If it is true that the institutional framework the Istituto is part of does not always prioritize the preservation of its scientific heritage, it is also true that as an important site of knowledge production - the Istituto witnessed much of this heritage. As such, it still offers at least two important avenues for its preservation - which in turn can open up to new possibilities, strengthening its international role as "haven for visiting limnologists" (Edmonson and Edmonson, 1990).

\section{Its memories}

The first of these avenues for the preservation of scientific heritage is the scientific publication issued by the
Istituto. Since its inception in 1942, soon after the foundation of the Istituto, the Memorie dell'Istituto italiano di Idrobiologia (Mem.) reached a broader audience than that of the local scientists based there. The Memorie successfully complemented the very few existing journals of limnological interest: the Archiv für Hydrobiologie, founded in 1906, and the Internationale Vereinigung für Theoretische und Angewandte Limnologie: Verhandlungen, first issued in 1922 as proceedings of the congresses of the International Society of Limnology (SIL). Both of these precursors to the Memorie were published by Schweizerbart science publishers, based in Stuttgart, Germany. A few years later, in 1948, the journal Hydrobiologia was also launched by Springer International Publishing. The flourishing of new journals dealing with general limnology or covering specific aspects of the discipline occurred in the second half of the last century. An exhaustive global list of limnological journals is maintained by the International Society of Limnology (SIL) and published on its website (https://limnology.org/links/).

Before the advent of metrics like impact factor, it was harder to quantify the relevance of scientific journals. Nevertheless, the high reputation the Memorie enjoyed is clearly reflected in the list of its published authors: many of the 741 papers published in 57 volumes from 1942 to 1998 are authored by world-famous scientists such as Evelyn Hutchinson, Ramon Margalef, W.T. Edmonson, Munro Fox, Adriano Buzzati, Luca Cavalli-Sforza, Franz Ruttner, Richard Vollenweider, Rob Peters, and Bob Wetzel. Building on this early success, the journal adapted to the changing landscape of scientific publishing, and became Open Access (OA) already in 1996, only three years after the introduction of this publishing model for scholarly peer reviewed journals, made possible by the advent of the Internet and the 1980s revolution in personal computing. In that year, only 161 scientific journals across all disciplines had adopted this form of distribution; in 2009, that number was to rise to 4767 , testifying to the success and importance of OA (Laakso et al., 2011). The early adoption of this format, and the possibilities opened up by the Internet, stimulated the further transformation of the journal: thus, in 1999, the Memorie changed its name to appeal to a more international audience, becoming the Journal of Limnology. In addition to adopting English as its official language and renewing its Editorial Board to strengthen its peer reviewed process, the journal also increased the frequency of publication to two issues per year (plus occasional supplements). Finally, in 2007, the journal consolidated its position in the new landscape of scientific publishing with the acquisition of the ISI Impact Factor. This scientometric and bibliometric index, now so central to scientific publishing, became widespread in the 1990s - after the purchase of the Institute for Scientific Information (ISI) by Thomson Scientific \& Healthcare, which mar- 
keted the Journal Citation Reports (or JCR) as a product of ISI Web of Knowledge. Other journal-level metrics, such as SCImago Journal \& Country Rank, were later added to this criterion for assessing the relevance of scientific journals. Achieving recognition in these metrics, however, proved particularly difficult in the case of the Memorie (and then $J L$ ) because of its in-house management based on volunteering, which struggled to compete with the professional management of commercial journals, ensured by solid and substantial financial support, as well as dedicated institutional infrastructures and expertise. To handle the increased number of submissions, the in-house management ceased in 2012, and the editor-in-chief provided the journal with a new editorial look, and a professional submission, peer reviewing, publishing and editing system, managed through a dedicated website (www.jlimnol.it). While the editorial process and the web presence is managed by PAGEPress, a professional publishing company, the peer review process is directed by the editors-inchief through the Associate Editors board, which includes 28 scientists from all over the word, and all subfields of limnology. Unfortunately, in 2016, the Istituto was forced to stop financing the publication of the journal due to a shortage in funding. As a result, the editors had to apply an article processing charge (APC) to ensure the journal's survival while preserving its editorial quality.

Despite the importance of scientometric and bibliographic tools and indexes in assessing scientific publications, as this case shows, these tools are not comprehensive, and can leave out much that is valuable from the point of view of scientific heritage. This is even clearer for pre-1990s journals and archives, whose digitization often still lags behind, and which are as a result left out of bibliometric analyses - as illustrated in the limited timeframe of existing bibliometric studies of limnology (Cole, 2009; Cao et al., 2012). In fact, as this brief overview of the journal's history shows, scientific journals like the Memorie are not only important because of the scientific results, findings, and data they publish. They also reflect and shape ongoing transformations in the scientific community and its institutions, practices, standards, and concerns. These aspects of the heritage of science are oftentimes not the direct and explicit object of scientific work: rather than appearing in the results and discussions, they tend to inform the materials and methods sections, as well as footnotes, acknowledgements, bibliographical references, and so on (Abrahamsson et al., 2015). Far from being only technical and hence of no historical or public interest, these sections of scientific publications, as well as scientific journals as a whole - along with their institutional transformations, are fundamental sources in the historiography of the sciences, and are a central component of the scientific heritage this article calls to protect. The historical name of the Journal of Lim- nology, the Memorie, meaning 'memories', successfully evokes this broader value of scientific journals as heritage of the history of science. To face the challenges of preserving the memories of limnology, while also protecting its future, then, a first important site to focus on is represented by scientific journals as historical archives of scientific activities: facilitating their preservation and facilitating access to their publication histories is a crucial step in the conservation of scientific heritage. Despite the already heavy pressures moulding the world of scientific publishing into different shapes, journals importantly also represent resources that could be made more accessible and better preserved at relatively little expense, but to great results. In the hope of helping in this effort, here we also offer a complete list of the 741 papers published on the Memorie from 1942 until 1998 as supplementary material (S1) for further study.

\section{Its instruments}

At the heart of limnological research is the study of data obtained through sampling, measuring, and analytical tools. The more sophisticated these instruments are, the more reliable, detailed, and abundant the data they enable us to acquire. For this reason, since its inception this discipline has also prompted researchers to take an interest in the development and use of appropriate and innovative analytical tools. As a result, many instruments and equipment were acquired, used, and eventually replaced during the long history of the Istituto. Many of them, having become obsolete, have been lost or discarded, and forgotten for years after being stored in some remote corner of the villa that since 1938 houses the Istituto. In 2015, one of the authors (RB) started recovering and restoring these instruments, gathering them in the former icehouse of the Istituto villa. Because of the remote location of this room, hidden (kryptē in Greek) within an artificial mound, this collection of historical limnological instruments was named Crypta Baldi, to honour the memory of Edgardo Baldi, the first director of the Istituto. To facilitate access, a virtual version of the museum is available online (vb.irsa.cnr.it/crypta). The breadth and diversity of this collection, along with its history of use and preservation, highlight some important features of the scientific heritage of limnology - and what we can learn from it today.

While the data collected thanks to scientific equipment is more readily recognized as valuable - as in the case of the long-term datasets the Istituto gathered since its foundation, as pointed out by one of the anonymous reviewers - instruments themselves usually tend to fade out of sight more quickly. Luckily there are important exceptions, as other scientific institutions also preserve collections of historical scientific instruments used in environmental research, like the Oceanographic Museum in Monaco (https://musee.oceano.org/) - whose 'Early Instruments' 
collection is easily accessible thanks to NOAA's (National Ocean and Atmospheric Administration, USA) Photo Library (https://photolib.noaa.gov/). Much more modestly, also the Crypta Baldi adds to this scientific heritage of instruments.

The instruments in the collection reach beyond the official history of the Istituto: as the villa already hosted limnological research during the life of De Marchi, some of the equipment inherited by the Istituto dates back to the early days of this discipline. This is the case of the foldable sampling boat (Fig. 1) named Pavesia (after Pietro Pavesi, an Italian trailblazer in the study of freshwater fauna), which was already described in a 1904 paper on alpine lakes. The author, Rina Monti, a pioneering limnologist, student of Pavesi, and the first Italian woman to hold a university chair, describes the boat as follows:

"The dinghy I use is made of double canvas, tarred and waterproof, it has an enclosed air space and

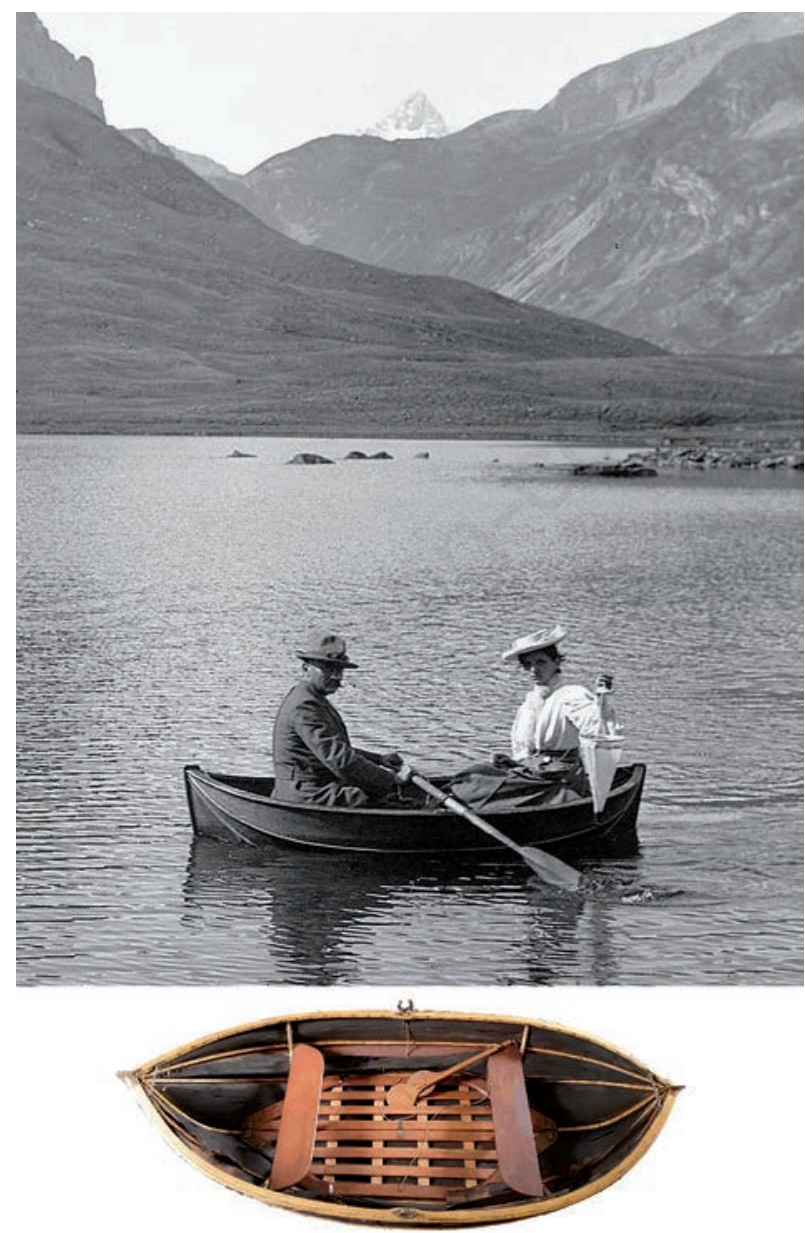

Fig. 1. Upper panel: Rina Monti sampling plankton on Lake Verney from Pavesia (1903). Lower pane: the Pavesia after its restoration in 2013. wooden ribs. Its weight is 25 kilos with oars and oar forks, it can be very easily closed like a fan and carried on the shoulder of a single person without any particular difficulty, as can be seen from the illustration provided. The length of the boat is 2 $\mathrm{m}$; its width, when open, is $1 \mathrm{~m}$; it is easy to launch and steer; its advantage is that it can be operated safely even in windy weather. The well-known company Pietro Baglietto in Varazze (Liguria) has built this small boat according to the specifications of Prof. Pietro Pavesi (Pavia) for the price of 270 Lire" (Monti, 1904).

Unlike most other instruments, whose restoration depended on volunteering work of one of the authors (RB), thanks to its charismatic character the Pavesia was restored on the occasion of the 75th anniversary of the Istituto, after spending almost 70 years in the attic of the villa.

Like the Pavesia, most of the earlier instruments were made to specification to fit the unique needs of limnologists: they needed to be used on the field, often in remote lakes, and so they needed to be sturdy and relatively light, as well as fit the idiosyncratic demands of the researchers who required them. This is the case of the sampling bottle (Fig. 2) and the wooden mounting for inverted thermometers pictured here (Fig. 3).

Dating these instruments is not easy, because of their artisanal character, but also since the inventory of the $I S$ -

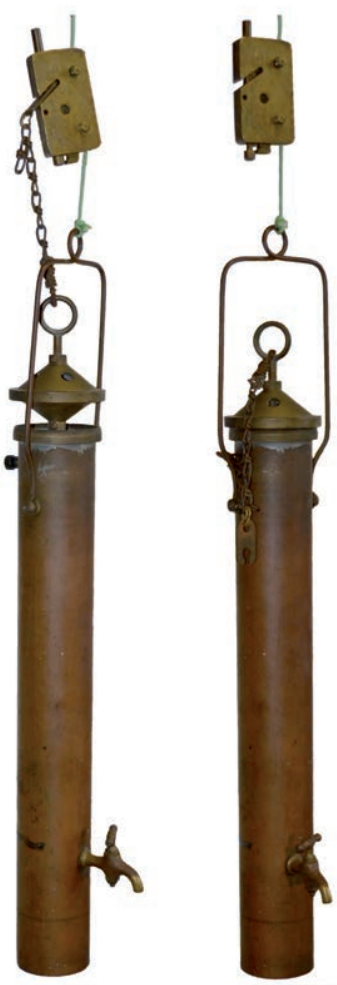

Fig. 2. Sampling bottle, open (left) and closed (right). First half of the last century, inventoried in 1941. 
tituto only started in 1940, and simply reported this date for many older instruments. Both relied on release systems operated through a messenger: once the desired depth was reached, launching the messenger along the rope would hit the release and either fill the bottle or reverse the thermometer and interrupt the mercury column, thus allowing to gather data and samples from specific depths. Even these earlier and simple instruments remind us of the cross-disciplinary character of limnology and prefigure the history that led the study of lakes as remote and relatively contained environments to the centre of ecological approaches (Monti, 1903). The cross-disciplinarity of limnology is also testified by the instruments that survived from the meteorological station De Marchi left to the Istituto: a pluviograph, a Fortin barometer, a Cantoni hygrometer, and the electromechanical recorder of a now lost anemograph built and marketed by Richard Frères in 1909.

The diversity of instruments required by the activities of the Istituto was already highlighted in the first issue of the Memorie (Baldi, 1942), where the first director, Baldi, dedicated a few pages - illustrated with photographs of the laboratories - to describe the scientific equipment available at that time. These photos provide a useful record of the use of several of the surviving instruments that are now preserved in the museum. For instance, Figure 4 pictures the Istituto chemistry lab in 1940. Visible on the laboratory bench are a Hellige Po-
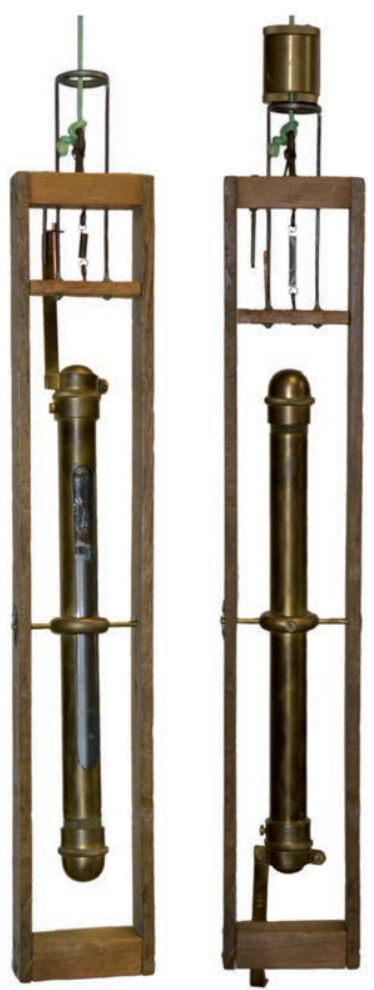

Fig. 3. Wooden frame for reversing thermometer, before (left) and after (right) sending the messenger,1920s-30s. tentiometer, manufactured by the firm F. Hellige \& Co, of Freiburg (Fig. 4.1), and, barely distinguishable on the back, a Galileo-Hellige colorimeter (Fig. 4.2). In the 1930s, the company founded in 1895 by Fritz Hellige began the industrial production of electronic medical devices. This potentiometer was powered by direct current and was equipped with a reference electrode (hydrogen or calomel) and a quinhydrone measuring electrode, which were stored in a compartment at the right of the measuring pan.

The colorimeter in figure 4.2 was produced by Officine Galileo, in Florence, presumably in 1940, and it relied on the fact that the absorption of white light by a coloured solution depends on the concentration of the solute and on the thickness of the solution layer through which it passes. If two beams of white light are passed through two solutions, one with a known concentration (reference solution) and the other with an unknown concentration (sample solution), the thickness of the sample can be adjusted to match the intensities of the transmitted light. Considering the two solutions side by side then
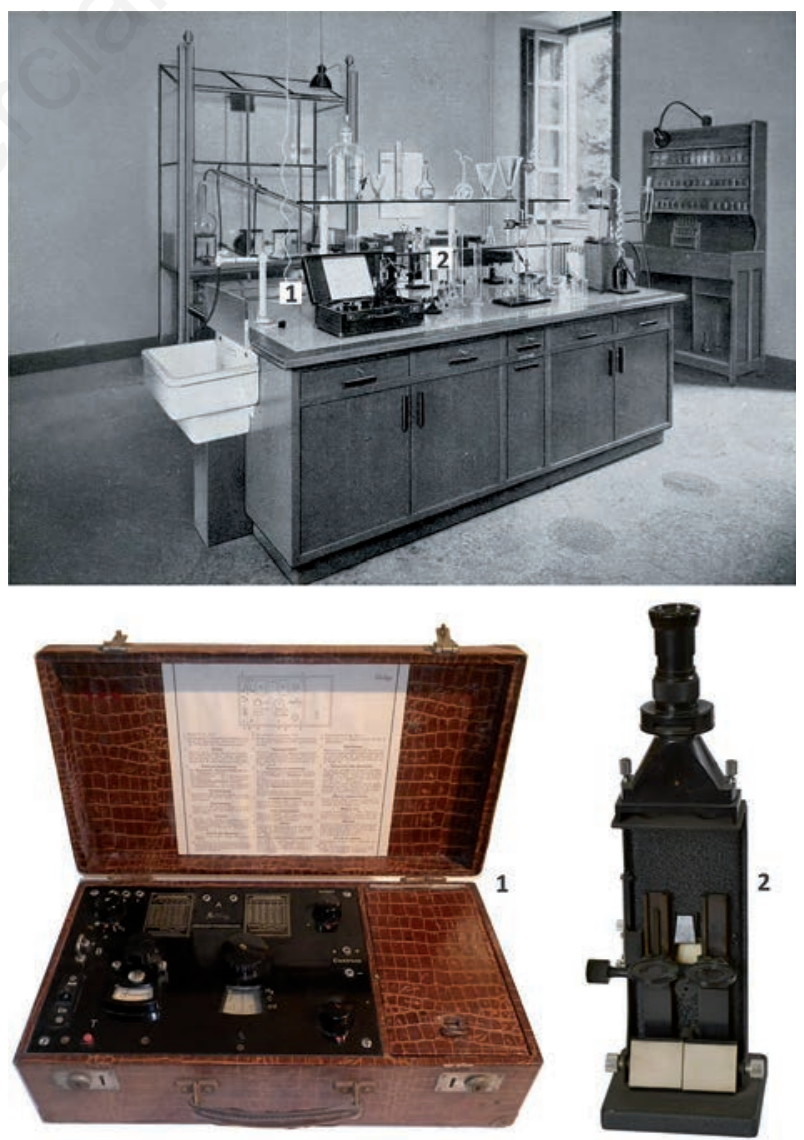

Fig. 4. Upper panel: The chemistry laboratory, 1940. Lower panel: 1. Hellige potentiometer, 1939; 2. Galileo-Hellige colorimeter, Officine Galileo, circa 1940. 
allows to determine the unknown concentration from the thickness variation produced by an equal intensity of transmitted light.

Another photograph from Baldi (1940) depicts the Istituto's photographic laboratory (Fig. 5), bearing witness to Baldi's great interest in microcinematography (Fig. 5.1) and microphotography (Fig. 5.2) as tools for documentation and research as well as for dissemination (Baldi, 1939; 1946). A bromograph (Fig. 5.3) was also available for the large-scale reproduction of photographs. The need to document and disseminate the results of limnological research led to the development of a microcinematography system for filming the microcosm hosted in lake waters (Fig. 5.1). It consists of a stand specially designed to couple a camera to a microscope. The camera (Siemens $16 \mathrm{~mm}$ mod. B., circa 1933 ) is equipped with a Bush Glaukar Anastigmatic $1: 2.8 / 20 \mathrm{~mm}$ lens. It is housed in the upper part of the stand, which couples it to a monocular microscope (Officine Galileo, late 1930s). This equipment was used to
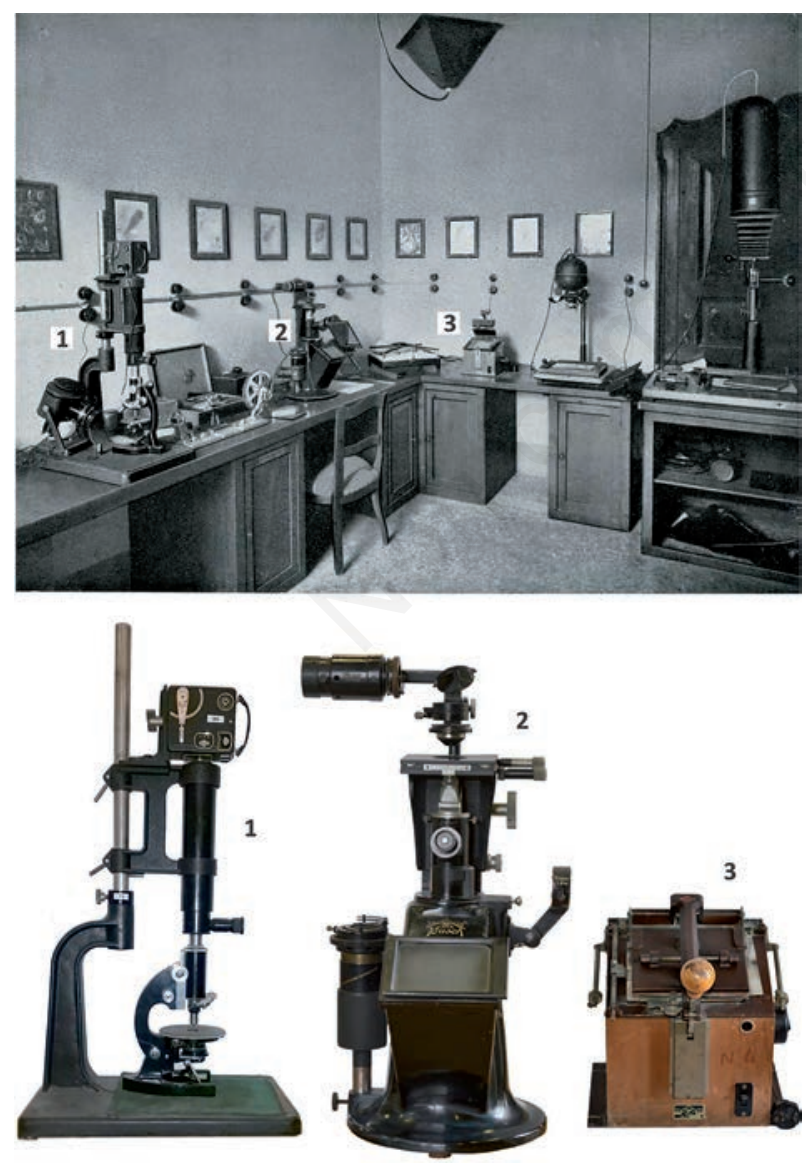

Fig. 5. Upper panel: The photographic laboratory, 1940. Lower panel: 1. Baldi's microcinematography system, end of the 1930s; 2. Busch "Metaphot" photographic microscope, 1938; 3. Agfa Bromograph, circa 1940. shoot a documentary on Lake Tovel at the end of the 1930s and other videos, which are also digitally available in the archive of the Istituto.

Using this Busch "Metaphot" photographic microscope (Fig. 5.2), equipped with an internal reflex camera, Baldi took many photos of plankton, still preserved in the photographic archive of the Istituto, which he used to illustrate his popular text (Baldi, 1939). This is an inverted microscope, i.e. built so that the specimen can be placed above the objective, suspended in liquid in a cell with transparent bottom. It is equipped with optics allowing enlargements from $3 \times$ to $2500 \times$, and allows observation in bright field and dark field, in reflected or transmitted light, and polarised light. The camera has an eyepiece with variable magnification, which can be adjusted simply by turning a dial. It is assembled in a rigid structure of compact design so that the focusing glass remains in front of the observer.

With these examples, which are only few of the more than 100 devices and pieces of equipment housed in the Crypta Baldi or, in some cases, displayed in the Istituto, we want to offer some snapshots of the heritage of limnology in this collection. While the episodic history we weaved along with these instruments is far from complete, it already allows to highlight some points that characterize the scientific heritage of limnological research at the Istituto. For instance, it underscores the continuing importance of cross-disciplinarity in this field, reminding us to preserve this trait despite the many challenges it now faces. The heritage described here also calls up the historical importance of documentation and dissemination, illustrating how science always reaches past its institutional and disciplinary boundaries, to share the wonders of the natural world beyond its community of specialists. While obstacles still plague the restoration and preservation of these instruments, still mostly based on the dedication of one of us (RB), we hope this brief overview of this particular portion of the scientific heritage of limnology can help in this ongoing task. The datasheets with descriptions and photos of all the instruments catalogued so far are presented here as supplementary materials (suppl. 2), and will hopefully also stimulate further research and preservation.

\section{CONCLUSIONS AND FUTURE PERSPECTIVES}

In this article, we offered a study of the scientific heritage of limnology through the specific case of the Istituto Italiano di Idrobiologia. Contextualizing this institution and its heritage within the historical frame of the field of limnology, we focused simultaneously on the history of limnology and on the preservation of its heritage, both material and immaterial. To contribute to this effort, we also sought to facilitate the access, study, un- 
derstanding, and preservation of this particular and often neglected scientific heritage in its various forms. In particular, we did so through the collections the supplementary materials focus on and their historical and conceptual framing in this article. Finally, we also meant this text as a call for the preservation of scientific heritage: despite its legal recognition in regulations and policies, scientific heritage is often marginal to broader concern with heritage preservation, like those of UNESCO. The scientific community cannot be the only one responsible for the preservation of this heritage, especially as the socioeconomic position of scientists becomes increasingly precarious and privatization and bureaucratization weakens their autonomy. It is important to open up broader discussions and make better efforts - in concert with specialists, historians, scientists, and other interested stakeholders, including the broader public - to ensure that the legacy of scientific research is not lost and forgotten, in a pile of debris rising under the wave of progress. As we showed, the history of science matters, since what we know of the world cannot be severed from how we know it, and how we can share it with others.

The current pressures mounting around a changing scientific community should not be allowed to distract us from the way we already walked, and from the many lessons we already learned along the way. Science, like any human activity, is a profoundly historical enterprise, one that cannot ever aspire to leave history and its limitations behind. Yet, understanding this history and its value - as well as protecting its heritage - is something that requires ongoing reflection and study of the past and the practical details of our apparatus of knowledge production. In the particular case of limnology we explored here, for instance, this means that we need to be mindful of the continued importance of this field's holistic and cross-disciplinary approach. The accumulation of scientific knowledge and data does not do away with the importance of reflecting on what matters in the past, what we should hold on to, and what should be left behind. If anything, it makes it all the more urgent and important, since how we do science today informs what kind of science will be possible in the future. Others have investigated the meaning and the significance of limnological research in the past (e.g. Rigler and Peters, 1995). We hope that looking at the scientific heritage of limnology will help us to continue along this path, because, to conclude, again, with Lourenço and Wilson: "The scientific heritage we preserve, study, and interpret - in its vertiginous change but also in its constant presence-is profoundly entangled with our millenary quest for knowledge about nature, the universe, and ourselves. It is profoundly entangled with what it is to be us" (Lourenço and Wilson, 2013).

\section{REFERENCES}

Abrahamsson S, Bertoni F, Mol A, Martín RI, 2015. Living with Omega-3: New Materialism and Enduring Concerns. Environ. Plann. D 33:4-19.

Baldi E, 1939. [Microcosmo. Cento tavole di vita invisibile]. [Book in Italian]. Hoepli, Milan: 217 pp.

Baldi E, 1942. [L'Istituto Italiano di Idrobiologia "Dott. Marco De Marchi”. Appendice].[Article in Italian]. Mem. Ist. Ital. Idrobiol. 1:347-364.

Baldi E, 1946. [Microfotografia e macrofotografia: principi e applicazioni della tecnica microfotografica al laboratorio di ricerche scientifiche e industrial].[Book in Italian]. Hoepli, Milan: 349 pp.

Cao X, Huang Y, Wang J, Luan S, 2012. Research status and trends in limnology journals: a bibliometric analysis based on SCI database. Scientometrics 92:735-746.

Cole JJ, 2009. Limnology as a discipline, p. 6-13. In: G.E. Likens (ed.), Encyclopedia of inland waters. Academic Press.

Corradini E, 2011. POMUI: The web portal of Italian university museums. UMACJ 4:77-84.

Edmondson WT, Edmondson YH, 1990. Palanza as a haven for visiting limnologists. Mem. Ist. Ital. Idrobiol. 47;15-60

Egerton FN, 2014. History of ecological sciences, Part 50: Formalizing limnology, 1870s to 1920s. Bull. Ecol. Soc. Am. 95:131-153.

Egerton FN, 2016. History of ecological sciences, Part 57: Aspects of limnology in America, 1930s to about 1990, led by Hutchinson and Hasler. Bull. Ecol. Soc. Am. 97:228-282.

Egerton FN, 2018. History of ecological sciences, Part 60: American Great Lakes before 2000. Bull. Ecol. Soc. Am. 99:77-136.

Fischer S, 2012. [Le limnimètre enregistreur transportable d'Edouard Sarasin].[Article in French]. Arch. Sci. 65:43-50.

Forbes SA,1887. The lake as a microcosm. Peoria Bull. Assoc. pp 77-87. Reprinted in Illinois Nat. Hist.Surv. Bull. 15: 537-550.

Forel FA,1892. Lake Geneva, Monograph of Limnology (three volumes, in French), volume II (1895). Librairie de l'Université Lausanne.

Hasok C, 2012. Is water $\mathrm{H}_{2} \mathrm{O}$ ? Evidence, realism and pluralism. Springer, Heidelberg: $316 \mathrm{pp}$

Hutchinson GE, 1957. A treatise on limnology, geography, physics and chemistry. J. Wiley \& Sons, New York: 1015 pp

Laakso M, Welling P, Bukvova H, Nyman L, Björk BC, Hedlund $\mathrm{T}, 2011$. The development of open access journal publishing from 1993 to 2009. PLoS One 6:e20961.

Lampert W, 2007. Limnology at Plön to vanish. An indication of a general trend? Sil News 50:2-3. Available from: https://limnology.org/wp-content/uploads/2015/08/silnews50.pdf

Lourenço M, Wilson L, 2013. Scientific heritage: Reflections on its nature and new approaches to preservation, study and access. Stud. Hist. Philosop. Sci. 44:744-753.

Manca M, Bertoni R, 2014. Seventyfive years of limnology at the Istituto Italiano di Idrobiologia in Pallanza. J. Limnol. 73:917.

Monti R, 1903. [Le condizioni fisico-biologiche dei laghi ossolani e valdostani].[Article in Italian]. Mem. Reale Istituto Lombardo di Scienze e Lettere 3-51. 
Monti R, 1904. [Limnologische Untersuchungen über einige italienische Alpenseen].[Article in German]. Forschungsber. Biol. Stat. Plön 11:252-275.

Mosello R, 2018. [L'archivio storico dell'Istituto per lo Studio degli Ecosistemi del CNR], p. 13-20. In: M. Canale, M. Gentilini, P. Guilizzoni and M. Manca (eds.), [Il Lago di Tovel].[Book in Italian]. CNR Edizioni.

Rigler FH, Peters RH, 1995. Science and limnology. Oldendorf/Luhe, Ecology Institute: 239 pp.

Sarasin E, 1879. [Limnimètre enregistreur transportable].[Article in French]. Arch. Sci. Phys. Natur. Genève 2:724-733.
UNESCO, 2003. Convention for the safeguarding of the intangible cultural heritage. Available from: https://unesdoc.unesco.org/ark:/48223/pf0000132540

Van-Praët M, 2004. Heritage and scientific culture: The intangible in science museums in France. Museum International $56: 113-121$.

Vecco M, 2010. A definition of cultural heritage: From the tangible to the intangible. J. Cult. Her. 11:321-324.

Vincent WF, Bertola C, 2014. Lake physics to ecosystem services: Forel and the origins of limnology. J. Limnol. Oceanogr. e-Lectures 4:1-47. 